\title{
Figurações do leitor no suplemento cultural: um estudo de caso do caderno Mais!' da Folha de S. Paulo
}

\author{
Figurations of the reader in the cultural supplement: a \\ case study of Mais! at Folha de S.Paulo
}

\author{
Marcelo Fernando de Lima
}

Jornalista formado pela Pontifícia Universidade Católica do Paraná (PUCPR), doutor em Letras pela Universidade Federal do Paraná (UFPR), professor titular do curso de Jornalismo da Universidade Positivo, Curitiba, PR - Brasil, e-mail: mandaprolona@yahoo.com.br

\section{Resumo}

O objetivo deste trabalho é, com base nas teorias da recepção, investigar como o leitor foi representado no suplemento cultural Mais!, do jornal Folba de S. Paulo, um dos cadernos de grande destaque nas década de 1990 e 2000 no país. O estudo parte da ideia de que uma publicação jornalística cria diversas imagens de seu público leitor e que essas representações se alteram com o passar do tempo, influenciadas por estratégias editoriais ou por outros fatores. Essas figurações nem sempre são definidas com clareza pelos jornais, embora seja possível percebê-las na leitura de textos que indicam, de forma direita ou por meio do uso de metáforas, a constituição de seu interlocutor. Neste trabalho, realizado a partir da análise de textos e de um banco de dados sobre o suplemento, verificamos mudanças na concepção do leitor do Mais!, o que sugere a diminuição de seu papel como mediador entre o público e a produção cultural.

Palavras-chave: Teorias da recepção. Jornalismo cultural. Mediação cultural. História do jornalismo. 


\begin{abstract}
The main purpose of this text is to investigate, by using reader-response theories, how the reader was represented in the supplement Mais!, published by Folha de S. Paulo, one of the most important cultural newspaper sections during the years 1990 and 2000 in Brazil. We begin the study by saying that every newspaper or magazine creates images of its own audience and those representations change as time passes, influenced by editorial strategies and other sort of change. The newspapers don't define those figurations clearly very often, although it's possible to perceive them by reading the texts which indicate, directly or by using metaphors, the constitution of the reader. In this work, undertaken through the analysis of texts and a database on the supplement Mais!, we found out changes in the concepts of the cultural newspaper reader and the lessening of its role as a mediator between the public and the cultural production
\end{abstract}

Keywords: Reader-response criticism. Cultural journalism. Cultural mediation. History of journalism.

\section{Introdução}

A década de 1950 é conhecida como a “época de ouro" do jornalismo impresso no Brasil. É um momento que ocorreu no interregno democrático entre o fim do Estado Novo e a ascensão do regime militar. Nesse período de maior liberdade e desenvolvimento econômico, os jornais aumentaram suas tiragens e aperfeiçoaram seus produtos, imprimindo ao trabalho um clima de maior profissionalização. Um passo importante para a época foi a reformulação gráfica e editorial dos veículos (ABREU, 1996).

Entre elas está a reforma do Jornal do Brasil, no Rio de Janeiro, levada a cabo em 1956, que incorporou novas técnicas de redação, criou cadernos, estabeleceu uma programação visual baseada na hierarquia e lançou o primeiro caderno de cultura moderno do país, o "Suplemento Dominical" (19561960). Também acompanhando essa tendência, foi criado na capital paulista o "Suplemento Literário" de O Estado de S. Paulo (1956-1974), que reuniu parte da intelectualidade brasileira, servindo de termômetro da produção cultural no país.

Nas décadas de 1950 e 1960 praticamente todo grande jornal contava com suplementos, espaços caros ao exercício da crítica - numa época de pouca pesquisa e divulgação nas universidades. Nas palavras de Benedito Nunes (2009), a imprensa era uma "caixa de ressonância" do que melhor se produzia em literatura e crítica da época.

Para Nunes, esse período foi um dos mais importantes para a crítica brasileira. A ideia era levar senso crítico ao leitor, procurando a renovação estética em várias áreas da produção artística. A principal razão para a proliferação dos suplementos foi o alto nível alcançado pela produção artística, sobretudo a literatura (NUNES, 2009). Atuando de forma didática e muitas vezes engajada, os suplementos queriam convencer o leitor quanto a valores estéticos e introduzi-lo numa nova forma de compreender as artes.

Na verdade, a maior oferta desses cadernos se deve à diminuição do espaço da literatura nos jornais. Isso porque, influenciadas pelos padrões norte-americanos, as empresas almejavam a profissionalização de seus quadros e o atendimento de necessidades práticas do cotidiano do leitor. A literatura foi direcionada para o segundo caderno ou para os suplementos. É a "desliteraturalização", caracterizando um divórcio entre o jornalista e o homem de letras. A criação dos suplementos foi uma alternativa para a falta de espaço da literatura nos jornais, criando ainda um novo atrativo para o leitor:

A literatura [...] passou a ser este algo mais que fortalece semanalmente os jornais, através de matérias de peso, imaginosas, reflexivas, opinativas e críticas, que tentam motivar o leitor apressado dos dias de semana a preencher de maneira inteligente o lazer do weekend. O suplemento tem também a sua raiz fincada no emprego do tempo burguês: a notícia que transmite a ação ocupa o burguês durante os dias de trabalho, enquanto a matéria literária 
que reclama o tempo da contemplação o envolve durante os dias de lazer (SANTIAGO, 2004, p. 164).

Nos suplementos culturais, a imagem do leitor-modelo intelectualizado prevaleceu até o início da década de 1980, quando ela começa a decair. Nos anos da Nova República, alguns poucos jornais e órgãos estatais mantinham veículos de cultura, como a Folha de S. Paulo, com o suplemento Folhetim (19771989), e as secretarias de Cultura do Paraná (Nicolau) e Minas Gerais (Suplemento Literário). Estudiosos destacam o distanciamento da crítica, ora praticada na universidade, e o jornalismo, influenciado cada vez mais pela lógica empresarial (SUSSEKIND, 1993; ROCHA, 2011).

$\mathrm{O}$ avanço da indústria cultural no país nos anos 1990, as medidas neoliberais do governo Collor - que reduziram o papel do Estado no patrocínio à produção cultural - e o agravamento de problemas educacionais contribuíram para a mudança do modelo de leitor nos suplementos. De uma forma geral, essas publicações começaram a se ater ao leitor jovem, interessado por cultura pop consumista, mas com pouco repertório de alta cultura. Os jornais deram destaque à informação, diminuindo o espaço dos textos mais longos e (ou) reflexivos. Em muitos casos, os cadernos tornaram-se roteiros de consumo de bens culturais simbólicos (JANUÁRIO, 2005).

Algumas alternativas a esse modelo, no entanto, foram criadas pelas próprias empresas jornalísticas. Procurando se firmar como um jornal de público intelectualizado, a Folha de S. Paulo apostou na criação, em 1992, do suplemento Mais!, que tinha por objetivo promover a cobertura dos grandes temas da produção cultural do país de forma crítica. Sua estratégia foi retomar, em muitos momentos, o modelo de leitor mais preparado que havia sido preterido nos anos 1980. Mesmo assim, a estratégia do suplemento foi dúbia: em alguns momentos, observamos também um movimento contrário a essa lógica, privilegiando o leitor-modelo menos familiarizado com o mundo da alta cultura.
O estudo da figuração do leitor no suplemento Mais! ${ }^{1}$ (1992-2010) traz pistas sobre a mudança do papel do jornalismo cultural produzido nos grandes diários e sua capacidade de mediar a produção artística no país. Verificamos uma mudança nessa figuração, cujas consequências são importantes para os rumos da produção e da circulação dos suplementos.

Este trabalho baseia-se na premissa de que todo emissor faz uma imagem mental do seu receptor, ou seja, ao codificar sua mensagem, ele imagina como esta será interpretada. Para discutir o tema, baseamo-nos em autores das teorias da recepção, entre os quais Wolfgang Iser, Umberto Eco, Stuart Hall.

\section{As figurações do leitor}

A inclusão da recepção nos estudos textuais é recente. $\mathrm{Na}$ teoria literária, o marco-zero foi a década de 1960, quando surgiram na Europa e nos Estados Unidos reflexões sobre o papel do leitor na construção do sentido e sua interferência na produção das obras.

Na comunicação, os estudos de recepção foram mais valorizados do final da década de 1970, sob a influência dos estudos culturais, que entendem a recepção como um movimento de resistência a mensagens hegemônicas. Fazendo uma releitura do dialogismo em Bakhtin, da hegemonia e da cultura popular em Gramsci, Stuart Hall (2006) propôs que o significado uma construção intersubjetiva e negociada, conferindo um papel importante à mediação.

Essa ideia já havia sido contemplada em teorias como a do leitor implícito (Wolfgang Iser) e do leitor-modelo (Umberto Eco). Para os autores, todo texto é composto de vazios ou lacunas; o papel do leitor, com seu conhecimento de mundo e seus mecanismos de interpretação, é completar o sentido. Segundo Iser, todo texto prevê o modo como deve ser lido. Ele forma e instrui o leitor. O leitor implícito figura uma imagem de leitor real, sugerindo

\footnotetext{
Pesquisa desenvolvida como parte do material apresentado ao doutorado em Letras (UFPR), concluído em 2010. Foram analisadas 665 edições do suplemento Mais!, envolvendo o período de 1992 a 2004. A partir desse número foi construída uma base de dados que serve para analisar diversos aspectos do suplemento nesse período.
} 
caminhos para que este teça o sentido. No encalço do leitor implícito, o leitor real se move sobre o texto de maneira ativa e passiva, ao mesmo tempo.

Para Iser, a comunicação perde seu efeito se o texto não consegue mudar as projeções do leitor ou quando elas ocorrem à revelia, ultrapassando os limites da interpretação. "O fracasso aí significa o preenchimento do vazio exclusivamente com as próprias projeções" (ISER, 2001, p. 88). Segundo o teórico, “[...] a relação entre o texto e o leitor só pode ter êxito mediante a mudança de representações do leitor, através da qual a assimetria começa a dar lugar ao campo comum de uma situação" (ISER, 2001, p. p. 88). A medida que entra em contato com o texto, o leitor forma um horizonte de referências, mudando ou ajustando suas projeções iniciais. A diferença entre os mundos do leitor e do texto proporcionam a interpretação.

Na mesma direção vai Umberto Eco, para quem todo processo de leitura é aberto e envolve relativa liberdade de interpretação. Conforme Eco (2005, p. 40), cada “[...] fruição é, assim, uma interpretação e uma execução, pois em cada fruição a obra revive dentro de uma perspectiva original". Alguns textos, no entanto, oferecem maior abertura interpretativa do que outros. Isso dependerá do lugar ocupado pelo texto e pelo momento histórico. $\mathrm{O}$ leitor-modelo "[...] é uma espécie de tipo ideal que o texto não só prevê como colaborador, mas ainda pode criar" (ECO, 2005, p. 14). Tal programação pode ser feita conforme o contrato de leitura, que varia com o gênero textual e com as formas de ler, que são referendadas socialmente.

Eco identifica dois tipos de leitor-modelo. O de primeiro é aquele que procura perceber as sutilezas do texto, tentando entender as relações entre forma e conteúdo. Além disso, busca relacionar a matéria da leitura com outros bens culturais simbólicos. O leitor-modelo de segundo tipo percebe apenas as informações referenciais, sem se ater às suas sutilezas de forma ou à intertextualidade. O teórico usa a metáfora do passeio no bosque para explicar as estratégias de interpretação: enquanto o leitor do primeiro tipo se arrisca livremente pelos cantos do bosque, o de segundo tipo prefere o conforto e a segurança do caminho principal.

Os suplementos representam um lugar privilegiado para a figuração do leitor, já que eles “[...] seriam ainda hoje um espaço de resistência à pressão da linguagem jornalística. São eles os cadernos onde os textos podem ser mais extensos, podem ser mais complexos e a linguagem mais refinada e menos coloquial" (TRAVANCAS, 2001, p. 55). Muito dessa caracterização do suplemento se deve à sua forma de leitura.

A partir da teoria de Eco e Iser, podemos entender o suplemento como uma "partitura" que deverá ser interpretada pelo leitor. São sinais deixados na página que preveem sua forma de interpretação, formando um leitor implícito, que fornecerá as pistas para o leitor real.

No Brasil, o jornalismo cultural se voltou, tradicionalmente, ao leitor-modelo de primeiro tipo: artistas, professores universitários, jornalistas, alunos dos cursos de pós-graduação das áreas de ciências humanas e sociais compõem esse grupo. A princípio, são leitores preparados para esse tipo de leitura, que passaram por aprendizagem, já que a leitura é uma forma de diferenciação social e requer treinamento (WILLIAMS, 2000, p. 92).

Mas a figuração do leitor não é fixa no tempo. $\mathrm{Na}$ história do jornalismo cultural brasileiro, a programação da leitura variou muito, conforme as influências sociais e culturais. Nos próximos segmentos, analisaremos como essas mudanças ocorreram, tomando como ponto de transição a década de 1980, e quais consequências trouxeram para o jornalismo como mediador entre o público e a produção cultural.

\section{O leitor da indústria cultural}

Os anos 1980 são uma época de transição do jornalismo brasileiro. Por um lado, os jornais reforçaram seu papel social de informar sobre os temas políticos e econômicos de maior destaque no período de abertura - apostando no leitor-cidadão (MATOS, 2008); por outro, foi nessa época que o jornalismo cultural começou a sofrer maior influência da lógica do mercado de consumo e da indústria cultural. O leitor, com menor preparo por ter se formado num sistema educacional enfraquecido, encontrou apelo fácil em matérias menos reflexivas, que miravam apenas a mercantilização da cultura.

A crítica autoral, comum nos suplementos de décadas anteriores, deu lugar a um noticiário de produtos culturais e roteiro de consumo. O leitor é visto como consumidor e não é incentivado a 
interpretar os produtos culturais. Para Sérgio Gadini, essa tendência tornou-se mais forte na década de 1980; está mesclada “[...] à preocupação por vezes coletiva em torno da condição de cidadania, numa perspectiva muito próxima à lógica do consumo" (GADINI, 2003, p. 53).

Marcelo Januário defende o jornalismo cultural mudou significativamente nos anos 1980, com a experiência da Ilustrada, da Folha de S. Paulo. A incorporação de novas tecnologias, o controle da produtividade nas redações e o maior "assédio" da indústria cultural levaram os jornais a produzirem uma massa maior de informações com pouco aprofundamento. "O discurso fragmentário [...] tornou-se padrão para veículos influentes como a Folha de $S$. Paulo, que, contrariando sua própria história, apostou na [...] infantilização de seu noticiário e público-alvo" (JANUÁRIO, 2005, p. 55).

Podemos entender como o leitor-modelo da Folha foi "programado" nessa época, conforme seu projeto editorial e gráfico: a adoção do didatismo para facilitar a leitura, linguagem leve e descompromissada, o foco no leitor-consumidor e com fraco repertório de alta cultura. Conforme resume o colunista Marcelo Coelho:

[...] tanto no caso dos produtos da cultura de massa quanto nos grandes momentos de cultura erudita que o jornalismo cultural tenta cobrir há muito pouco o que ler além do "guia", porque não há muita coisa sobre o que pensar. O texto do jornalismo cultural está me expulsando para fora dele (é o que faz a propaganda, aliás) - vá ver isso, não vá ver aquilo, começou isto, começou aquilo. Mas não traz discussão (COELHO, 2003, p. 136).

A década de 1980 marcou o distanciamento entre a esfera jornalística e literária. O jornalismo já havia herdado uma aversão à crítica acadêmica, o que estava em curso na década anterior, quando algumas universidades brasileiras assimilavam a complexa terminologia do estruturalismo francês. Luiz Costa Lima (1981, p. 196) chamava a atenção para o fato de os jornais darem importância excessiva às novidades e não conseguiam, por falta de preparação, lidar com as teorias, limitando-se à divulgação.

Walnice Nogueira Galvão (2002, p. 5) entende a crise do jornalismo cultural numa perspectiva histórica: ela faz parte do desmonte da cultura brasileira promovido pela ditadura militar. Segundo a pesquisadora, a forma de tratar a cultura imposta durante o regime, com o incentivo populista à indústria cultural, foi mantida pelos governos do período democrático. Para ela, os próprios produtores “[...] se empenharam numa campanha de deseducação, infantilizando o público (caso do cinema), imbecilizando-o (caso da televisão), tratando seu ouvido como penico [...]" (GALVÃO, 2002, p. 9).

O resultado foi uma produção acanhada em três décadas, sem experimentações e ousadias, tendo como única baliza o mercado. A decadência da crítica é resultado desse estado de coisas. Galvão completa: em vez de ocupar os jornais, ela se refugiou na universidade, adotando uma linguagem cifrada e "indigesta", graças à especialização acadêmica; a crítica jornalística, por sua vez, tornou-se superficial e meramente "digestiva", mirando apenas o gosto médio.

\section{Da indústria cultural à alta cultura}

$\mathrm{Na}$ década de 1990, o jornalismo cultural enfrentou problemas que iam além das pressões financeiras e da mudança do perfil do leitor: nessa época acontece ampliação ainda maior da influência da indústria cultural e o surgimento da internet comercial. O aumento da oferta de produtos audiovisuais passou a interferir no tempo e na forma de leitura. Além disso, as empresas de comunicação sofreram com as oscilações da economia, ora representando aumento de público (primeiros anos do Real), ora um período de recessão (o final da década de 1990, com a crise da moeda).

Já no início do Plano Real, houve um aumento de oferta de bens culturais simbólicos para as classes $\mathrm{C}$ e $\mathrm{D}$. Acreditando no potencial consumidor desse público, as empresas de comunicação "simplificaram" seus conteúdos para se adaptar à nova audiência. Ao apostarem na ampliação, os maiores jornais brasileiros tomaram uma série de medidas, como reformas gráficas e editoriais, privilegiando textos mais curtos e simplificados, além da utilização de mais informação visual e venda de jornais associada a brindes.

Embora houvesse uma pequena ampliação do acesso, piorou o repertório cultural do público. 
O jornalista Otávio Frias Filho, diretor da Folha de S. Paulo, confirma essa mudança. Referindo-se ao público dos anos 1990 em diante, ele afirmou que apenas 20\% dos leitores da Folha são críticos, passaram por formação e têm bom repertório. Os $80 \%$ restantes representam o leitor "[...] menos politizado, [que] tem menos tempo para ler o jornal [...]. É um público que faz uma leitura, digamos, não só mais rápida, mas também mais utilitária, mais seletiva, do jornal" (FRIAS FILHO, 2008, p. 212).

Para atrair o leitor, os jornais tiveram que criar diferenciais. A Folha de S. Paulo apostou no lançamento do Mais!, suplemento cultural que reunia editoriais como literatura, ciências, artes e espetáculos e que circulou entre fevereiro de 1992 e novembro de 2010, totalizando 995 edições. A partir da análise de suas edições, identificamos três fases distintas: 1) 1992-1999, voltada para o leitor-modelo da indústria cultural; 2) 1999-2004, voltada para o leitor-modelo da alta cultura; e 3) 2004 a 2010, novamente para o leitor da indústria cultural.

Os primeiros editores do Mais! destacam o fato de a publicação ter sido criada em meio a uma crise de fornecimento de papel, o que levou o suplemento a reunir uma série de cadernos que foram extintos. Mesmo assim, a estratégia de mercado era "renovar o jornalismo brasileiro" (LEITE NETO, 2010, p. 8). Assim, o suplemento conjugava a necessidade pragmática de atender o leitor da indústria cultural, despreparado e com pouco repertório, a uma aspiração mercadológica que procurava vender o Mais! como produto diferenciado, que visava o leitor da alta cultura.

Na primeira fase do suplemento, publicado em formato standard, a opção por atender ao leitor da indústria cultural, mas com um produto "embalado" numa diagramação diferenciada, foi evidente. Isso pode ser notado na organização editorial e gráfica do caderno. Optou-se por preservar o didatismo das matérias da Folha. Além disso, a maior parte das matérias dessa fase foi produzida por jornalistas.

O gênero mais comum nessa fase foi a reportagem, correspondendo à metade das chamadas de capa $(51,9 \%)$, seguida de entrevista $(16,6 \%)$, ensaio $(13 \%)$. Ao analisarmos a edição de 5 de julho de 1992, por exemplo, percebemos que a maior parte dos textos é assinada por jornalistas da própria Folha $(73,3 \%)$ contra apenas $26,7 \%$ relativos a colaboradores externos.
Mais do que a simples figuração do leitor da indústria cultural, há uma indecisão no projeto editorial quanto a que tipo de público se reportar. Embora procurasse divulgar, em suas resenhas, o lançamento de livros considerados "importantes" pelo jornal e por intelectuais ligados à universidade, toda semana havia uma reportagem mostrando a pesquisa dos livros mais vendidos, cujo critério de divulgação era apenas mercadológico, mirando o leitor-consumidor.

Um "antídoto" adotado por alguns articulistas do Mais! foi a reação a certas opiniões que defendiam a literatura de massa dentro do próprio suplemento. A polêmica mais famosa foi travada entre o romancista best-seller Paulo Coelho e a articulista Marilene Felinto. No artigo "Mulheres que leem bobagens", Felinto comentou a pesquisa do Datafolha que mostrava o público feminino como o responsável pela ampliação das vendas de livros de autoajuda e de romances açucarados.

Felinto associa a ascensão da literatura comercial à construção machista de um imaginário feminino submisso, gerando leitoras acomodadas e sem autonomia intelectual. Para a jornalista, as leitoras buscam os livros de autoajuda e os romances açucarados como uma "válvula e escape", ou seja, furtam-se aos desafios e prazeres da leitura da grande literatura:

Hesitando entre a rudeza do discurso feminista e a hostilidade da competição no mercado profissional, ela buscaria refúgio no mito da delicadeza, do amor romântico ou mesmo imaculado como o da Virgem: afinal sua relação erótica já não seria com o homem que de noite ronca a seu lado e de dia compete com ela; seria com o livro, com o personagem, com o guerreiro mágico, Deus e Cristo, que a levasse desse mundo terreno para uma fuga paradisíaca qualquer onde ela "vencesse na vida", como sempre vencem as heroínas de Sheldon (FELINTO, 1995, p. 3).

Paulo Coelho partiu para o contra-ataque na semana seguinte; defendeu a formação de novos leitores com a literatura de massa e criticou o posicionamento da "elite" intelectual brasileira, que supostamente vira as costas para o "gosto médio". Coelho afirma: "Face à realidade irrefutável, a 'elite' 
cultural, querendo continuar 'elite', proclama: 'os leitores são burros"' (COELHO, 1995, p. 3).

Apesar das reações contrárias ao "gosto médio", o suplemento não se furtou, na sua primeira fase, a cobrir a ascensão do livro de massa. Foram publicadas diversas reportagens e notícias sobre o tema, como a cobertura das bienais do livro, os campeões de vendas, pesquisas com leitores. Os lançamentos e relançamentos de livros foram tão importantes no suplemento que correspondem a 39,8\% das capas do Mais!. Nesse caso, o valor-notícia é a atualidade ou a comemoração de alguma efeméride, por exemplo: centenário de morte ou nascimento de um autor, 50 anos da publicação de uma obra clássica etc.

A abordagem da literatura foi conservadora. Usava-se um nome consagrado pela crítica, que era discutido no jornal de forma didática e palatável ao leitor médio. Isso refletiu um estado de coisas do próprio mercado editorial dos anos 1990 e início do século XXI: descapitalizadas, as editoras investiram mais em traduções e na "redescoberta" de autores consagrados. Nisso, intensificaram uma relação de simbiose com o jornalismo cultural, por meio do lobby de seus assessores de imprensa e departamentos de marketing.

A estratégia de privilegiar o leitor médio foi abandonada em partes no final de 1999, na segunda fase do Mais!, em que o suplemento procurou o leitor mais qualificado, criando estratégias para melhorar seu repertório. Uma delas consistiu em publicar guias de leitura de livros de várias áreas das humanidades - escolhidos por intelectuais ligados a universidades, e não mais por jornalistas. Em vez do ranking dos mais vendidos, passou a ser divulgado o ranking dos melhores autores em diversas áreas. Nessas edições, foram escolhidos os melhores romancistas, poetas e autores de não-ficção. A edição fazia as vezes de um guia de leitura, fornecendo algumas dicas de leitura desses textos.

Outra estratégia foi a formação de uma equipe de articulistas nacionais e internacionais de diversas especialidades, tais como Robert Kurz, Richard Rorty, Marilena Chauí, José Arthur Giannotti, Jacques Rancière, Sergio Paulo Rouanet, Bento Prado Júnior, Slavoj Zizek (filosofia), Peter Burke, Evaldo Cabral, Bóris Fausto, Manolo Florentino, Kenneth Maxwell (história), Augusto de Campos, Luiz Costa Lima, Juan José Saer, Javier Marías (literatura), Jorge Coli (arte), Jurandir Freire Costa (psicanálise), Hermano Vianna (antropologia), Milton Santos (política).

O jornal adotou também um novo projeto gráfico. As edições passaram a ser numeradas, para facilitar a organização do suplemento numa coleção, no formato de fascículo, como se integrasse uma espécie de enciclopédia, feita com o objetivo de atualizar e ensinar o leitor sobre os variados temas da produção cultural. Ao ser publicado em tabloide, o Mais! tornou-se um produto "suplementar", fácil de ser colecionado devido ao formato.

Analisando a edição de 30 de dezembro de 2001, podemos verificar que a participação dos jornalistas diminuiu $(18 \%)$ e a dos colaboradores externos aumentou $(82 \%)$. O gênero ensaio passou a ser preponderante na edição $(43,9 \%)$. O segundo gênero mais importante foi a entrevista $(15,4 \%)$ e o terceiro, a reportagem $(11,7 \%)$.

Essa transformação pôs em evidência uma nova compreensão do leitor-modelo no jornal. $\mathrm{O}$ jornalista deixava de ser o intermediário entre o leitor e o tema especializado do universo cultural. Agora, o especialista falava direto ao leitor, por meio do ensaio, gênero textual híbrido geralmente relacionado a um tipo de leitor mais qualificado. No lugar das reportagens e entrevistas (news) entraram os ensaios analíticos (views). A divulgação da cultura dá lugar à reflexão sobre ela, num formado que é, ele próprio, um bem cultural. Os olhos do leitor é puxado para o jogo entre forma e conteúdo que está na linguagem, e não apenas para o que está fora dela (os bens culturais).

Sobre esse aspecto, Luiz Costa Lima defendia que a presença do intelectual e do professor universitário é fundamental para levar ao leitor os grandes debates: "Tal presença permite que se cogite na formação de um leitor que não se contente com a mediocrização que o cerca. Se isso se der, a universidade passará a contar com um dos apoios de que atualmente carece: o apoio do público [...]" (LIMA, 2000, p. 13).

De 2005 até o fim do suplemento, em 2010, o Mais! voltou para o formato standard, privilegiando grandes reportagens e traduções. Houve uma queda no número de colunistas externos e aumento de textos sobre atualidades, refletindo um redirecionamento da estratégia da Folha em face da crise do jornalismo gráfico devido à internet. O Mais! tornou-se uma revista semanal, como 
uma espécie de "continuação" das abordagens da Folha nos dias de semana, e não mais como um "suplemento", um "algo mais" para o leitor diferenciado.

Apesar da aparente separação entre os dois tipos de leitor nas três fases do jornal, eles se misturam em boa parte do tempo. Na verdade, essa mescla é típica da produção cultural midiática da década de 1990 em diante, preocupada com as vendas, mas também com o consumidor cult, que constrói sua identidade a partir da fruição de produtos culturais, estabelecendo elos com uma comunidade que consome esse tipo de bens simbólicos.

O consumo de determinados bens culturais é referendado socialmente e torna-se uma maneira de diferenciação em relação à massa. O domínio dos códigos culturais é favorecido por mecanismos de reprodução que se encontram na família e na escola. Trata-se de uma espécie de "herança", a que a massa comum dos leitores não tem acesso. Dessa forma, o acesso à alta cultura é distribuído de forma desigual e por isso mesmo é capaz de diferenciar as pessoas (MAIGRET, 2010, p. 189). Podemos afirmar que a leitura diária dos jornais promove a formação de uma comunidade, que interpreta o mundo de forma semelhante.

Uma das metáforas que podem ser usadas para se entender a formação de comunidades diferenciadas de leitores é a culinária, assunto que tem se tornado cada vez mais evidente nos jornais. O leitor-modelo do suplemento cultural é um público supostamente mais sofisticado, que vai consumir o bem cultural como se saboreasse um prato "assinado" por um chefe de cozinha.

Dessa forma, para esse leitor que constrói sua identidade cultlendo o Mais!, "[...] nada de prazeres vulgares e fáceis, nada de gostar do que é igual para todos. Agora todo mundo tem que ter personalidade e bom gosto - sempre definidos por seu padrão de consumo" (VIANNA, 2003, p. 12). O suplemento seria uma forma de combater a massificação (fast-food) da produção cultural brasileira.

Esses consumidores "[...] não admitem mais aqueles sabores rudes que um dia encantaram a sociedade de consumo em seus tempos primitivos, pré-digitalizados e pré-globalizados" (VIANNA, 2003 , p. 12). O uso de um discurso supostamente mais intelectualizado pode ser entendido como uma forma de criar, no público, uma identidade com um produto que dê a aparência de sofisticação, mas que na verdade é massificado.

\section{Considerações finais}

Ojornalismo cultural brasileiro cumpriu um papel relevante na formação de leitores no século XX. Esta ação foi decisiva entre as décadas de 1950 e 1980, quando os suplementos não apenas divulgaram as principais linhas da produção artística e forneceram chaves para a compreensão dessas obras, mas também se tornaram, eles próprios, espaços privilegiados de leitura, exigindo do leitor um exercício apurado de interpretação. Os suplementos eram "caixas de ressonância" da produção artística do país, principalmente a literária. Os grandes críticos e escritores passavam, necessariamente, por suas páginas.

Essa realidade mudou a partir da década de 1980, quando o jornalismo sentiu maior influência da indústria cultural, cujos agentes passaram a pressionar a imprensa em busca de maior divulgação. Além disso, ele foi atingido pelo enfraquecimento da produção artística no país, consequência tardia das políticas da ditadura militar. Sobrevivendo de maneira residual, algumas publicações tentaram investir na qualificação dos leitores, mas sem muito sucesso.

Na década de 1990, a Folha de S. Paulo tentou conquistar o público mais qualificado com o suplemento Mais!, sem abrir mão da oportunidade de ampliar o número de leitores médios. Podemos considerar que o suplemento, em certa medida, foi importante na atualização do leitor sobre tendências da crítica e da produção cultural, já que pode ser considerado o mais importante das últimas duas décadas, mas assumiu uma posição ambígua quanto à definição do público: na primeira e na terceira fases se voltou ao leitor médio; na segunda apostou no leitor qualificado.

O resultado disso é que o suplemento não conseguiu nem contemplar as necessidades de um público de massa, nem oferecer um produto diferenciado para o leitor com maior formação. Quanto ao conteúdo, apresentou uma cobertura pouco ousada, mais preocupada em conservar os espaços de escritores e artistas consagrados do que se arriscar em autores pouco conhecidos. Na verdade, não conseguiu dar cobertura ao que se produziu de novo na época. Esta foi feita à margem da grande imprensa, 
por publicações alternativas, muitas vezes bancadas pelos próprios artistas ou instituições privadas.

Com isso, percebe-se uma falha do suplemento na cobertura da produção artística e na sua mediação com os leitores: não conseguiu qualificar ou ampliar o público, e ofereceu uma abordagem conservadora sobre a produção cultural da época, trazendo pouca contribuição para o seu aperfeiçoamento. Essa característica particular do Mais! pode ser entendida como consequência da segmentação na imprensa, e uma forma geral: em meio a um mercado de bens culturais cada vez mais especializado, os velhos suplementos dos jornais perderam, aos poucos, os seus principal diferenciais, que são refletir sobre a produção cultural do país numa determinada época e formar leitores críticos.

\section{Referências}

ABREU, A. Imprensa em transição. Rio de Janeiro: Editora FGV, 1996.

COELHO, M. Jornalismo cultural. In: NESTROVSKI, A. (Org.). Um país aberto: reflexões sobre a Folha de S. Paulo e o jornalismo contemporâneo. São Paulo: Publifolha, 2003. p. 134-137.

COELHO, P. Em defesa da leitura. Folha de S. Paulo, 5 fev. 1995. Mais!, p. 3.

ECO, U. Obra aberta. São Paulo: Companhia das Letras, 2005.

FELINTO, M. Mulheres que lêem bobagens. Folha deS. Paulo, 29 jan. 1995. Mais!, p. 3.

FRIAS FILHO, O. Entrevista. In: SANT'ANNA, L. O destino do jornal: a Folha de S. Paulo, O Globo e O Estado de S. Paulo na sociedade da informação. Rio de Janeiro: Record, 2008.

GADINI, S. L. A cultura como notícia no jornalismo brasileiro. Rio de Janeiro: Prefeitura da Cidade do Rio de Janeiro/Secretaria Especial de Comunicação Social, 2003.

GALVÃO, W. N. Musas sob assédio. Folha de S.Paulo, 17 mar. 2002. Mais!, p. 5-11.

HALL, S. Da diáspora: identidades e mediações culturais. Belo Horizonte: Editora UFMG, 2006.
ISER, W. A interação do texto com o leitor. In: LIMA, L. C. (Org.). A literatura e o leitor: textos de estética da recepção. São Paulo: Paz e Terra, 2001. p. 83-132.

JANUÁRIO, M. O olhar superficial: as transformações do jornalismo cultural em São Paulo na passagem do século XXI. 2005. Dissertação (Mestrado) - USP, São Paulo, 2005.

LEITE NETO, A. + Mais! (1992-2010). Folha de S.Paulo, 16 maio 2010. Mais!, p. 8.

LIMA, L. C. Dispersa demanda: ensaios sobre literatura e teoria. Rio de Janeiro: Francisco Alves, 1981.

LIMA, L. C. Marginais aqui e lá. Folha de S.Paulo, 4 jun. 2000. Mais!, p. 12.13.

MAIGRET, É. Sociologia da comunicação e das mídias. São Paulo: SENAC, 2010.

MATOS, C. Jornalismo e política democrática no Brasil. São Paulo: Publifolha, 2008.

NUNES, B. A clave do poético. São Paulo: Companhia das Letras, 2009.

ROCHA, J. C. C. Crítica literária: em busca do tempo perdido? Chapecó: Argos, 2011.

SANTIAGO, S. O cosmopolitismo do pobre. Belo Horizonte: Editora UFMG, 2004.

SÜSSEKIND, F. Papéis colados. Rio de Janeiro: Editora UFRJ, 1993.

TRAVANCAS, I. O livro no jornal: os suplementos literários dos jornais franceses e brasileiros nos anos 90 . São Paulo: Ateliê Editorial, 2001.

VIANNA, H. O direito de querer menos. Folha de S. Paulo, 21 dez. 2003. Mais, p. 12.

WILLIAMS, R. Cultura. São Paulo: Paz e Terra, 2000.

Recebido: 15/08/2012

Received: 08/15/2012

Aprovado: 05/09/2012

Approved: 09/05/2012 